\title{
Agressividade no Espelho de Lacan Ou Sobre a Agressividade como Resultado da Formação do Eu
}

Luiz Fernando Botto Garcia

\section{Resumo:}

É n'O estádio do espelho como formador da função do eu que Jacques Lacan dirige esforços de modo a elucidar o fenômeno psíquico do narcisismo. Nele, o autor mostra como a formação da noção de eu na criança acontece a partir de uma relação alienante de identificação com o outro, processo que tem na agressividade um dos seus resultados mais importantes. $\mathrm{O}$ presente artigo visa transcorrer os principais temas do Estádio do Espelho, de modo a caracterizar a agressividade como seu fator consequente.

Palavras-chave: psicanálise lacaniana-imaginário-desejo-agressividade. 


\section{Subjetivação, Falta, Desejo}

René Descartes, logo no começo de sua segunda meditação, diz que "esta proposição, eu sou, eu existo, é necessariamente verdadeira todas as vezes que eu a enuncio ou que a concebo em meu espírito" (DESCARTES, I973, p. IOO). Eis a consciência cartesiana escapando da dúvida hiperbólica e do gênio maligno. Consciência essa que é a causa única de sua própria descoberta: o "eu”, sujeito da proposição, é autossuficiente, autônomo em relação à existência de qualquer outro ser que não ele mesmo.

Consciência autoidentitária? Autonomia do eu? Ilusões!, dirá Jacques Lacan. É com o aviso de uma contraposição a qualquer filosofia oriunda do cogito que começa $O$ estádio do espelho como formador da função do eu tal como nos é relevada na experiência psicanalítica (I966).

Para quebrar essa estrutura autoidentitária, Lacan partirá do resultado empírico de uma experiência de psicologia comparada de Henri Wallon: uma criança adquire a noção de corpo próprio a partir de uma imagem externa, seja a sua própria projeção especular, seja a imagem de outra criança de mesma idade (já em Wallon encontramos a noção de espelho como um termo "genérico", que pode ser, além do próprio espelho, uma relação de "espelhamento" com um semelhante). O bebê pode, então, superar a angustiante vivência de um "corpo despedaçado" e assimilar uma noção de unidade corpórea que lhe era até então estranha. A partir da noção de corpo próprio, a criança consegue separar o que faz parte de si (corpo, emoções, pensamentos) e o que lhe é exterior. Essa mudança acontece pelo processo de identificação com a imagem especular, processo esse que será a estrutura de toda constituição de seu eu, dentro do campo subjetivo do imaginário, marcado essencialmente pelo narcisismo.

Porém, se a noção de um eu surge a partir de uma imagem exterior a si, toda formação da subjetividade será então uma alienação. O espelho não será uma simples vivência da infância, mas "uma estrutura, um modelo de vínculo que operará durante toda a vida" (BLEICHMAR, N. M.; BLEICHMAR, C. L., I992). O eu é um lugar de alienação por excelência. É nesse sentido que Lacan poderá chamar o estádio do espelho de um processo "ontológico"I do ser humano. Assim, como escreve Ogilvie, o estádio do espelho terá muito pouco de estádio e de espelho (I988, p. IO7).

Essa imagem especular - que, tomando a forma de Gestalt, é absorvida pela criança - ganha um caráter mais constituinte do que constituído. Entra em cena

I Expressão forte, que poderia abrir espaço para uma interpretação a-histórica da subjetivação. Discussão pertinente, que não nos cabe aqui fazer: determinar a relação entre o caráter históricoestrutural com o ontológico do estádio do espelho. 
a noção de imago: uma imagem que assume um papel ativo na formação do eu, através de sua aparição enquanto eu-ideal: imagem salutar, edificante, pois é essa relação com a imago que determinará a "dialética das identificações", cuja essência é ser identificação com o outro.

Se a imago determina um processo de alienação por meio de identificações objetivantes, existirá no eu uma dependência constitutiva em relação ao outro, cujo desconhecimento ${ }^{3}$ será base do pensamento de autoidentidade e auto nomia do sujeito moderno. "Essa relação erótica, em que o indivíduo humano se fixa numa imagem que o aliena de si mesmo, eis aí a energia e a forma donde se origina a organização passional que ele irá chamar de seu eu" (LACAN, I966, p. II3). O eu, então, "se constitui em alguma coisa radicalmente outra: a forma antecipada daquilo que ele não é, mas que não há outra possibilidade de não crer senão que é" (OGILVIE, I988, p. II2). Mas, se Ogilvie escreve sobre uma "forma antecipada", é porque a Gestalt especular reflete no bebê uma condição (tanto orgânica quanto mental) que ele ainda não possui.

É necessário pontuar que, até aqui, usamos o termo "eu" de modo indiscriminado. O eu que é resultado do processo de identificação é o "sujeito do inconsciente", "je”, enquanto que, para o eu que é uma ficção de autoconsciência resultante do desconhecimento da estrutura alienante do "je”, eis o "moi", o ego freudiano. Nesse texto, usamos o termo eu para a primeira significação, “je”.

Juntamente com as experiências de Wallon, a teoria do Estádio do Espelho é tributária da filosofia de Alexandre Kojève e sua interpretação - bastante singular - da dialética hegeliana. Kojève (2002) leu a dialética do senhor e do escravo como chave de compreensão da Fenomenologia do Espírito. Para Kojève, o homem se diferencia dos animais pelo seu desejo (que é sempre uma ação negadora) de algo que ultrapassa o real dado. Se um primeiro momento (o desejo de negação de coisas empíricas - consumo) tem algo em si de positivo, o momento posterior deve ser a superação (no sentido aufhebun) desse momento positivo, ou seja, a negação do próprio negativo. Nesse sentido, só podemos desejar algo que seja plenamente negativo, e esse algo é o próprio desejo. Mas não qualquer desejo: desejamos o desejo do outro.

Desejar um desejo é pôr-se no lugar do valor desejado por esse desejo. (...) Desejar o desejo do outro é, em última análise, desejar que o valor que eu sou ou que represento seja o valor desejado por outro (KOJÈVE, 2002, p. I4).

2 Para a crítica de um mau uso do termo "dialética” em Lacan, ver ARANTES, in: SAFATLE, 2003.

3 "O desconhecimento representa uma certa organização de afirmações e negações, a que o sujeito está ligado. (...) É preciso que haja atrás do seu desconhecimento um certo conhecimento do que há a desconhecer" (LACAN, I983, p. I94). 
Partindo de Kojève, Lacan chegará a uma teoria do desejo puro ao dar um caráter negativo a esse desejo (que, portanto, terá muito mais a ver com o Begierde de Hegel e Kojève do que com o Wunsch de Freud). Negatividade que será marcada pela falta de um objeto empírico que realizaria o desejo.

Gestalt, imago, identificação, desejo do outro: o obscuro narcisismo primário ganha determinações concretas em Lacan, que poderá então dar outro significado para conceitos tão importantes na psicanálise. Entre eles, a agressividade, enquanto consequência do processo de subjetivação que se inicia no estádio do espelho, será o resultado de nossa análise.

\section{O Filósofo e o Médico}

Foram os seminários de Kojève, que o então psiquiatra passara a frequentar a partir de 1933, que deram o tom da reviravolta lacaniana dentro do campo psicanalítico, por meio da teoria do desejo. Pois é essa teoria que irá fundamentar uma ideia já cara a Lacan desde sua tese de doutorado: a necessidade de uma irredutibilidade social do indivíduo. No Hegel de Kojève não existe sujeito fora da relação com um não-eu apreendido pela consciência. E o desejo tem papel fundamental nessa relação:

A satisfação do desejo é a assimilação do outro, seu não-ser, na imediata transformação deste. Na ação kojeviana, o desejo destrói uma realidade objetiva para o satisfazer e cria, em seu lugar, por meio da própria destruição, a realidade subjetiva (TORRES, 2004, p. 317).

O desejo atua, nesse esquema, enquanto mediação entre duas consciências. Se o desejo do homem é o desejo do outro, o fator determinante para a fundamentação da consciência será a relação intersubjetiva. Em Kojève, a luta pelo reconhecimento resultará na dialética do senhor e do escravo, que marcará o primeiro modo de relação entre as consciências, estágio superado por meio do trabalho pela figura do escravo. Essa luta acontece pela necessidade que tem uma consciência em se fazer valer frente ao desejo de outra, para que esta reconheça o valor da primeira enquanto autônoma e livre de determinações. O conflito seria uma incompreensão do caráter negativo dos desejos, pois impor meu reconhecimento ao outro não é outra coisa senão uma luta de "puro prestígio", que aliena a minha condição frente ao desejo alheio. As consequências que tiram Kojève dessa relação intersubjetiva, como o fim da história, dirão muito pouco a Lacan, mas o cerne da teoria kojèviana terá uma influência decisiva na constituição do Estádio do Espelho. As temáticas do desejo enquanto mediação e falta e a turbulência das relações sociais darão uma das chaves de compreensão da teoria do imaginário lacaniana. 


\section{Gestalt e a Antecipação da Forma}

Na conferência "Algumas reflexões sobre o ego" (I95I), Lacan escreve que o sintoma histérico diz respeito a uma noção de corpo que não é funcional, mas sim uma expressão simbólica de uma "anatomia imaginária", que se relaciona com as ideias do indivíduo a respeito de seu corpo próprio. "Isso acontece como se a imagem corporal tivesse uma existência autônoma de si, e por autônoma eu quero dizer independente da estrutura objetiva”.

Quanto a isso, diz Lacan, todos esses fenômenos nada mais fazem senão "exibir as leis da Gestalt" - Gestalt essa que seria uma "boa forma que fornece um princípio global de organização da percepção" (SAFATLE, 2005, p. 78). Essa forma de apreensão da imagem diz algo além da percepção completa dos objetos pela imaginação (oposta à percepção parcial da simples visualização). Ela determina o modo como o visível pode aparecer, pois "organiza o visível como campo" (op. cit.) ${ }^{4}$.

Porém, o fato da noção de corpo próprio provir do imaginário subjetivo é uma consequência de um dado biológico a respeito do nascimento humano: a fetalização. Lacan aponta o "inacabamento anatômico do sistema piramidal, bem como de certos resíduos humorais do organismo materno" como confirmação dessa prematuração do nascimento. Daí o psicanalista falar em "deiscência do organismo", "discórdia primordial" (I966, p. 96): para Lacan, a vivência do bebê é marcada por uma incompletude orgânica e experiência psíquica de desamparo.

Um dos reflexos da fetalização é a má formação do córtex visual: o bebê demora meses para reconhecer formas complexas, como a do corpo humano. A constatação de Wallon mostra que é somente a partir do sexto mês de vida que ele pode reconhecer a forma corpórea, por meio da experiência do espelho.

Mas não só o córtex visual precisa de certo período pós-nascimento para completar seu desenvolvimento. Aos seis meses de idade, época em que a experiência walloniana torna-se possível, o bebê ainda não tem sua formação - tanto cerebral quanto motora - completa. Ao ver-se no espelho, ele antecipa, mesmo que por alguns segundos, uma correção de postura (parecendo, assim, maior do que é), ao mesmo tempo em que harmoniza sua relação com o corpo, marcada pela angústia da desunificação, assumindo essa forma ideal harmoniosa, maior e unificada, além de invertida, de seu corpo próprio. A expressão jubilosa do bebê diante do espelho seria consequência da esperança de ir além de sua vivência da falta que a imagem especular supera: "Sua alegria é

4 Sobre uma relação do modo de organização gestaltista do campo visual com a categorização kantiana do espaço, ver o próprio Safatle, 2005, p. 80. 
devida ao triunfo imaginário em antecipar o grau de coordenação muscular que ele ainda não alcançou" (LACAN, I95I). Esse caráter antecipatório da Urbild, da imagem primordial, é resultante da própria forma gestaltista da imagem:

\begin{abstract}
Para um sujeito, assumir uma imagem seria, pois, ao mesmo tempo, assumir um princípio geral de organização do campo do visível, assim como um princípio geral de apreensão global e de desenvolvimento. (...) lembremos que as imagens do corpo funcionariam como imagens-tipo que regulam o desenvolvimento dos indivíduos por meio de um processo de formação que é con-formação à espécie. (SAFATLE, 2005, p. 78).
\end{abstract}

De modo a exemplificar a função antecipatória - e, portanto, formadora - da imagem, Lacan faz dois empréstimos da etologia animal ${ }^{5}$. Trata-se de dois processos de identificação, um homeomórfico e outro heteromórfico. Quanto ao primeiro, o autor refere-se a dois fatos: uma pomba tem suas gônadas desenvolvidas após visualizar qualquer outro indivíduo de sua espécie, ou até mesmo a sua própria imagem refletida; algo semelhante ocorre com a larva do gafanhoto, que pode desenvolver-se para uma forma gregária ou solitária, sendo a imagem de um indivíduo de uma dessas formas (ou até mesmo outro objeto que tenha forma e movimentos similares a esses indivíduos) que irá determinar o seu modo de vida adulto. "Formação que é con-formação à espécie".

Já para o segundo processo de identificação - heteromórfico - Lacan dará um lugar de destaque à teoria do mimetismo de Roger Caillois: pensar o mimetismo enquanto simples resultado do processo evolutivo de adaptação seria dar à natureza um meio de desenvolvimento um tanto quanto miserável. Pois há nos organismos uma capacidade de fascinação quanto ao espaço e suas formas, já que o indivíduo sofre uma série de determinações a partir de sua relação com o meio ambiente.

E é de Caillois que Lacan fará o gancho para a etologia de von Uexküel: existe uma relação bastante singular entre cada organismo (Innenwelt) e seu meio ambiente (Umwelt). A percepção dos objetos de um lugar em si não é a mesma para cada uma das diferentes espécies que ali habitam: "a estruturação do mundo em forma de Umwelt faz-se pela projeção de um certo número de relações, de Gestalten, que o organizam, e o especificam para cada animal" (LACAN, I983, p. I94). E, como não poderia ser diferente, o meio ambiente humano, seu Umwelt, não diz respeito a um ambiente físico, mas sim ao meio social.

Desde a tese de 1932, Da Psicose Paranóica em suas relações com a Personalidade,

5 Simanke aponta para o uso de modelos etológicos enquanto modo de oferecer uma forma de contraponto ao risco de elaborações puramente metafísicas (SIMANKE apud SALES, 2005, p. I20). 
Lacan preocupou-se com o sujeito enquanto tal na sua individualidade, percebendo aí o quanto tal individualidade é efeito do meio social, meio humano por excelência (CHAVES, s.d., p. 2).

Como consequência dessa relação com seu Umwelt, é a produção do meio social que marcará o processo de conhecimento da forma humana. "Lacan lembra que pensar o corpo é desvelar um modo de percepção e de ação que corta o contínuo da existência para configurar um meio ambiente vivido. Essa configuração é conformação à imagem” (SAFATLE, 2005, p. 83). Pois, na experiência do espelho, a criança reconhece o próprio corpo a partir da forma corpórea: a síntese psíquica que unifica o corpo faz-se enquanto reconhecimento da forma humana enquanto tal.

\section{Imago e a Alienante Relação do Eu com a Alteridade}

O bebê, que até então vivia a experiência de um corpo psíquico despedaçado e faltoso, além de uma nebulosa e falha separação entre interior e exterior, unifica seu eu em função da Gestalt humana. Ao fazê-lo, toma para si uma imagem que não diz respeito a quem ele é. $\mathrm{O}$ reflexo especular - harmônico, maior, invertido, unificado - aparece enquanto uma imagem de um ideal Ich eu-ideal. É a partir dessa relação com a imagem que Lacan poderá recuperar de Jung o termo "imago": imagem investida libidinalmente, que dá o seu caráter formador. Ela determina o modo de ação e de escolha, pois determina as propriedades (que, portanto, pouco têm de objetivas) de um objeto no campo do visível (organizado pela forma Gestalt). A imago seria, pelas próprias palavras de Lacan, uma "relação psíquica por excelência" (LACAN, I95I). Ela faz do objeto um alvo de projeção, um reflexo do eu que o enxerga. Na experiência do espelho, a imagem ganha aspecto de imago porque se torna o reflexo infiel de quem se olha e não vê a si, mas a uma forma humana ideal.

Se, nesse momento, o sujeito não consegue enxergar o objeto senão enquanto um reflexo de si - ou ao menos em parte - o olhar desse eu é um olhar narcísico.

É a imagem de seu corpo que é o princípio de toda unidade que ele [o homem] percebe nos objetos. (...) é sempre ao redor da sombra errante do seu próprio eu que vão se estruturando todos os objetos de seu mundo (LACAN, I985, p. 2II).

É esse caráter "egomórfico" dos objetos que dá, no narcisismo, a incapacidade do indivíduo ir além da projeção de si. Os objetos ganham, então, uma "polivalência instrumental” e uma "polifonia simbólica" (LACAN, I966, p. III). 
Essa imagem externa ${ }^{6}$, investida libidinalmente, é a chave de entrada para a trama relacional socioestrutural - entrada que, na modernidade, faz-se através da família. Pois, ao identificar-se com a forma humana, o homem apreende uma estrutura global, que é internalizada e tomada enquanto constitutiva de si mesmo: assumindo um ponto, a imagem de si, o indivíduo assume a rede inteira de relações sociais: apreender uma imagem é apreender um processo. A internalização dessa trama relacional dá ao sujeito um princípio de desenvolvimento, que dirá respeito tanto ao modo de se posicionar na estrutura quanto à organização do seu próprio desejo.

Os objetos aparecem como uma projeção do eu ${ }^{7}$, que, por sua vez, organiza-se a partir de uma estrutura corporal ideal, dada pela Urbild. Porém, como negamos a imediaticidade do cogito, todo processo de formação do eu deverá partir de algo externo à consciência de si. Pode-se, já na relação com a imagem especular do eu-ideal, determinar uma relação com o outro: "que o eu seja um 'eu-ideal' já significa que ele seja um 'outro eu'” (SALES, 2005, p. II8). Essa relação de identidade com algo diferente de si, ou seja, o processo de "constituição da identidade através da alteridade por duplicação de uma imagem própria que o indivíduo carrega consigo" (ARANTES, in SAFATLE, 2003, p. 53), dá ao eu um caráter alienante.

A saída para a angústia do despedaçamento é então a identificação com essa imagem especular cuja Gestalt é responsável pela condução do processo de constituição do 'eu'; saída que é, no entanto, ilusória, pois vem alicerçada sobre um fundo inapelável de alienação (SALES, 2005, p. II6).

Não há nada de próprio na imagem de si. As imagos formadoras da subjetividade são identificações com o outro, processo que se origina a partir da relação entre a criança e o reflexo especular: "a criança é capturada por uma imagem essencialmente alheia, sua identidade própria nunca poderá deixar de ser algo que lhe vem de fora, do horizonte da alteridade" (op. cit.).

A alienação criada pela relação com o outro se mostra de dois modos: estar na imagem (pôr-se fora de si), e também no ato de desejar o desejo do outro. O primeiro modo, vimos até aqui, é a identificação com a imago do eu-ideal, identificação com a Gestalt humana. Já o segundo é mais complexo, porque pode ser subdividido: a sentença "o desejo do

6 Ogilvie atenta para o fato de que a exterioridade em questão não é a realista, sendo o próprio eu uma exterioridade de si mesmo.

7 "O fato objetivo, como a imagem, é diverso conforme o estado interior com que o abordamos" (PROUST, I989, p. 95). 
homem é o desejo do outro", extraída de Kojève, tem, ao menos, duas interpretações.

No Hegel de Kojève, o desejo, que é puramente negativo, apenas se satisfaz se alcançar outro objeto também puramente negativo, que só pode ser o próprio desejo. Nesse sentido, uma consciência vai desejar o desejo de outra, mas o fará de modo a desejar ser desejada, ou seja, desejar ser o objeto de desejo de outra. Daí Kojève falar em luta por reconhecimento, que termina necessariamente com a morte de ao menos uma das consciências, ou com a relação dialética entre senhor e escravo. Em ambas as situações, o resultado não será o pretendido pelas consciências protagonistas: com a morte, obviamente termina qualquer possibilidade de reconhecimento, assim como, havendo um vencedor, esse não será reconhecido por outra consciência livre, mas por um escravo que, ao não arriscar a própria vida e abrir mão de sua liberdade, não se difere do animal. $\mathrm{O}$ escravo reconhece o senhor enquanto tal, enquanto consciência livre. Mas o senhor, ao reconhecer o escravo como escravo, não pode ser reconhecido por uma consciência livre e, portanto, não tem realizado o seu desejo de reconhecimento. Só será satisfeito "aquele que foi escravo, que passou pela sujeição, que suprimiu dialeticamente sua sujeição" (KOJĖVE, 2002, p. 23). A dialética do senhor e do escravo seria a abertura fenomenológica para a liberdade, por meio da figura do escravo e seu reconhecimento pelo trabalho.

A segunda interpretação teria um sentido que chamaremos (faux de mieux) de "estrutural" - socialmente determinado - diferente da primeira, de viés fenomenológico. Desejar o desejo do outro é desejar o objeto de desejo do outro. Nesse sentido, o social faz a mediação entre os desejos. Pois toda relação entre sujeito e objeto é mediada pelo reconhecimento do objeto enquanto socialmente visado. Não existe um desejo objetal imediato, livre de determinação social. Apesar de não ser o foco de sua análise, essa possibilidade de interpretação também se faz presente em Kojève: "é humano desejar o que os outros desejam, porque eles o desejam" (op. cit., p. I3).

Como é comum em Lacan, muitos enunciados são propositadamente polissêmicos. Do ponto de vista epistemológico, há um cruzamento entre as racionalidades fenomenológica e estruturalista na obra de Lacan, que pode ser reconhecido nessa dupla interpretação a respeito do desejo ${ }^{8}$. Mas isso não significa exatamente que ele se afaste de Kojève. Por um lado: Kojève também foi fortemente influenciado pela fenomenologia existencialista (especialmente por Heidegger). Por outro lado: Lacan, no momento em que lança esse adágio, de fato acrescenta perspectivas à sua própria interpretação do desejo que não

8 Lacan não separa as interpretações. Aqui o fazemos de modo analítico, mas entendendo que ambas atuam concomitantemente. 
têm origem em Kojève - mas o faz preservando a leitura kojèviana. As duas possibilidades não só convivem, como confluem em um ponto: o caráter alienante do desejo. Desejar um objeto ou mesmo desejar ser o objeto de desejo do outro são formas positivas, que escapariam à negatividade do desejo.

\section{Agressividade}

Passemos brevemente pela tese de doutorado de Lacan. No caso Aimée, o então psiquiatra apontou para a grande influência que a protagonista sofreu de sua amiga e de sua irmã, que agiram sobre a personalidade da doente como "protótipos", de função afetiva e representativa (LACAN, I987, p. 253). Afetiva, pois Aimée sentia-se rebaixada, humilhada moralmente frente à superioridade da irmã enquanto esposa e mãe, e frente à extroversão da amiga, qualidades que lhe causavam inveja, sentimento que nos leva ao caráter representativo do protótipo: ambas representavam, para Aimée, um ideal - a irmã na vida conjugal, a amiga na vida social.

Dados os diferentes ambientes conceituais da tese e do Estádio do Espelho, já podemos enxergar nessa análise um germe da relação entre o eu e o outro. Pois o protótipo atua analogamente ao eu-ideal, que, no caso de Aimée, aparece refletido na imagem da irmã e da amiga. Porém, psicótica, Aimée não consegue vivenciar a identificação com esses ideais senão de modo bastante invasivo, traumático. Pois, na paranoia, não ocorre a identificação estabilizadora com a ordem normativa paterna: "há uma fixação que impede o sujeito de atravessar as relações de rivalidade e alienação com o que lhe aparece como ideal" (SAFATLE, 2007, p. 20). O ataque à atriz, motivo da internação final de Aimée, foi caracterizado por Lacan como um ataque a si mesma, "autopunição": a culpa gerou em Aimée o encontro com a normatividade da lei, o que, para Lacan, explica a cura da paranoia após o crime, já que a ausência dessa normatividade fora a causa da doença.

Ao atacar a atriz, Aimée atacava o seu "protótipo" (pois a atriz seria a representante da extroversão da amiga). "A mesma imagem que representa seu ideal é também o objeto de seu ódio" (LACAN, I987, p. 254). Do ódio para a agressividade, o salto é semântico: ambas as expressões dizem respeito a uma sensação interna ao sujeito, causada pela proximidade invasiva entre eu e outro. No caso de Aimée, a agressividade alcança o limite da sua resolução, a agressão.

Mas a agressão é um raro extremo. Pois, como mostra Lacan na tese II de $A$ agressividade em psicanálise (I966), "a agressividade, na experiência, nos é dada como intenção de agressão e como imagem de desmembramento corporal" (p. Io6). Tratemos da parte final dessa tese: agressividade e desmembramento.

Lacan aponta para algumas práticas sociais como maneira de apresentar uma 
relação bastante singular do homem com seu corpo: a circuncisão e a tatuagem (práticas primitivas ainda em voga), e a maneira "procustiana" com que a moda remodela o corpo, em detrimento de sua forma natural. O psicanalista também faz breves pinceladas sobre o tema de uma brincadeira comum entre as crianças, que é o desmembramento de bonecos, ou mesmo a fantasia de desmantelamento do próprio corpo. Ambas as situações dizem respeito ao que Lacan chamou de "imagos do corpo despedaçado" (op. cit., p. IO7) - que, assim como aparecem constantemente nos sonhos, também o fazem nos quadros de Hieronymus Bosch imagos que tratam exatamente dessa relação agressiva com o corpo. O primeiro exemplo mostra como essa agressividade alcança um caráter social, enquanto o segundo mostra-a como um reflexo espontâneo infantil. Ambos têm relação com a vivência (anterior ao processo de unificação do eu) do corpo polimórfico e libidinal. A agressividade seria uma relação de estranhamento com o próprio corpo enquanto unidade, resultado da alienação da primeira vivência corpórea do bebê, perdida na unificação especular. Unidade do eu, noção que, como vimos, não é natural, já que surge a partir da identificação com a imagem da Gestalt humana, com a imagem do outro.

Existe, assim, uma discrepância entre a imagem especular e a sensação corporal, discrepância essa que "é vivida primeiramente como rivalidade porque a unidade do reflexo (ou da imagem alheia) sublinha a falta de uma unidade real desejada" (SALES, 2008, p. 33). Essa relação agressiva com o próprio corpo será a fonte da energia necessária para a identificação com o genitor do mesmo sexo:

A energia dessa identificação é dada pelo primeiro surgimento biológico da libido genital. Mas é claro que o efeito estrutural de identificação com o rival não é evidente, a não ser no plano da fábula, e só é concebível se tiver sido preparado por uma identificação primária que estrutura o sujeito como rival de si mesmo. De fato, o toque de impotência biológica encontra-se aqui, assim como o efeito de antecipação característico da genes e do psiquismo humano, na fixação de um 'ideal' imaginário (LACAN, I966, p. II7).

Lacan, seguindo Freud, entende que, para que exista um narcisismo secundário (elemento fundamental na formação do complexo de Édipo), fazse necessário o narcisismo primário. A relação de rivalidade entre pai/filho ou mãe/filha é consequência da rivalidade do indivíduo consigo mesmo.

Antes de chegar à tese central de seu texto, Lacan analisa a agressividade dentro da clínica psicanalítica. É sob forma de transferência negativa que o paciente manifesta seus impulsos agressivos: "esse fenômeno representa, no entanto, a transferência imaginária, para nossa pessoa [para o analista], de uma das imagos mais ou menos arcaicas (...), que, por uma ação de identificação, 
deu sua forma a tal instância da personalidade" (I966, p. IO7). A agressividade não deve ser bloqueada, mas sim dirigida pelo analista, pois é um sintoma que conta algo bastante importante a respeito do sujeito que o produziu. Como mostra a central tese IV do mesmo texto, esse sintoma é resultado do processo de identificação narcísico: "a agressividade é a tendência correlativa a um modo de identificação que chamamos narcísico, e que determina a estrutura formal do eu do homem e do registro de entidades característicos de seu mundo" (op. cit., p. IIO).

Podemos retomar aqui a dupla chave de leitura que fizemos da máxima kojèviana de que o desejo do homem é desejo do outro. Sobre a primeira, já em Kojève encontramos uma referência bastante clara à agressividade: a "luta por reconhecimento" é consequência direta da necessidade que a consciência tem de tornar-se o desejo de outra, de modo a caracterizar a sua liberdade como algo além do negativo e do indeterminado, dando à liberdade um aspecto concreto, por meio de sua mediatização pelo desejo do outro. Em Kojève, a agressividade alcança o nível de uma disputa de morte, mas Lacan não precisa de tanto: basta a expressão da agressividade para que a criança identifique em seu genitor a figura do punidor.

O caráter expressivo da agressividade está longe de ser algo necessariamente moderno, e o exemplo que Lacan vai buscar em Santo Agostinho assim o mostra. Agostinho descreve uma cena de ciúme infantil, onde uma pequena criança, de idade anterior ao aprendizado da fala (estágio infans), olha de forma colérica para o irmão menor, no colo da mãe. O colo é o lugar desejado pelo pequeno, que vê no irmãozinho o seu rival: o desejo dessa criança é ser desejada pela mãe, e ser carregada no colo é dar concretude ao desejo de ser desejada. Nesse sentido, o colo da mãe, enquanto lugar onde se encontra o desejo maternal, acaba por excluir da criança a condição de sujeito: aliena para o outro materno o reconhecimento e a realização do seu desejo. É por isso que podemos achar bastante provável que essa criança, conseguindo o colo materno, tivesse reações agressivas para com a própria mãe.

Para além da luta por reconhecimento, encontramos o que Lacan chamou de "concorrência agressiva" (I966, p. II3). Aqui, já não se trata mais de desejar o lugar de desejo do outro, mas desejar o "objeto do desejo do outro" (op. cit.), que é o princípio formador da tríade eu, outro e objeto (entramos, portanto, na interpretação social do desejo). É a partir do desejo do outro que configuro o meu objeto de desejo. O objeto faz a mediação social entre o eu e o outro: o meu objeto de desejo é o objeto de desejo do outro, pois desejar não é um ato imediato. O social, enquanto estrutura maior das relações intersubjetivas, diz quais objetos são dignos de serem desejados, e é por meio desse objeto que se instala uma relação de concorrência entre eu e outro. E como a relação de objeto não trata apenas de coisas, podemos lembrar que existe algo de social na beleza, tendo 
a moda o papel histórico de determinar quais serão as formas corporais a serem desejadas. Portanto, "o desejo do sujeito só pode, nessa relação, se confirmar através de uma concorrência, de uma rivalidade absoluta com o outro, quanto ao objeto para o qual tende" (LACAN, I983, p. I98).

Trata-se de um processo de identificação: desejar o objeto de desejo do outro é pôr-se no lugar desse outro. A identificação com a imagem do outro tem aqui um papel fundamental, já que "identificar-se com o outro significa querer tomar seu lugar, adquirir para si seus adjetivos, o que, levado às últimas consequências, significa suprimir sua existência (EVANS apud SALES, 2005, p. I22)". Aimée feriu alguém que representava o seu ideal: a autopunição foi uma tentativa de ferir a si mesma ${ }^{9}$. Assim como Kojève o fez, podemos identificar nas relações de conflito uma ameaça de morte - que, portanto, tem mais a ver com suicídio do que assassinato. Mas se o filósofo pensou o resultado do conflito pela relação dialética entre senhor e escravo, o psicanalista irá fazê-lo pelo próprio narcisismo - que, por internalizar a imagem do outro "não deixa de demarcar um forte teor de servidão” (SALES, 2005, p. I23).

A própria origem da identificação a partir da imago especular - da Gestalt humana pela forma do outro - já dá uma razão de ser à agressividade, afinal, "mediante a imagem, as identidades são naturalizadas" (SAFATLE, 2005, p. 79). Essa fixidez é uma das causas, na estrutura narcísica, do eu ser fonte de agressividade, pois quanto mais tenta fugir da alienação, mais se depara com sua alteridade original. "A constituição do eu já é sua própria destruição" (BOWIE apud SALES, 2005, p. I23).

À guisa de conclusão, podemos dizer que, tanto em $O$ estádio do espelho quanto em Agressividade em psicanálise, Lacan aponta para uma teoria então por fazer. Pois ao tratar da experiência especular como algo muito além da pura experiência, a psicanálise avança sobre o terreno da estrutura, que precisou ganhar a roupagem linguística para alcançar não mais esse narcísico pequeno outro, mas o Outro, grande Outro, a mediação simbólica, que determinará de outro modo o desejo, para além da alienação.

9 A agressividade narcísica diz respeito a uma tensão intrapsíquica que Lacan designou na fórmula "um ataque ao seu inimigo é um ataque a si mesmo" (I95I). 


\section{Referências Bibliográficas}

ARANTES, P. E. "Hegel no espelho de Lacan". In: SAFATLE, V. (org.). Um limite tenso: Lacan entre a filosofia e a psicanálise. São Paulo: Unesp, 2003.

BLEICHMAR, N. M.; BLEICHMAR, C. L. A psicanálise depois de Freud: teoria e clínica. Porto Alegre: Artes Médicas, I992. Disponível em: <http://br.geocities. $\mathrm{com} /$ jacqueslacanigoirg8I/textos2/lacanteoriadosujeito.htm $>$. Acesso em I2/06/2008.

GHAVES, W. G. A noção lacaniana da subversão do sujeito. S.d. Disponível em: $<$ http://www.pol.org.br/publicacoes/pdf/revista2002_04_art7.pdf>. Acesso em I5/06/2008.

DESGARTES, R. Meditações metafísicas. Col. Os pensadores. São Paulo: Abril Cultural, I973.

KOJÈVE, A. Introdução à leitura de Hegel. Rio de Janeiro: UERJ, 2002.

LACAN, J. Écrits. Paris: Seuil, I966.

- Da psicose paranoica em suas relações com a personalidade. Rio de Janeiro: Forense Universitária, I987.

O seminário. Livro I: Os escritos técnicos de Freud. Rio de Janeiro: Jorge Zahar, I983.

O seminário. Livro 2: $\mathrm{O}$ eu na teoria de Freud e na técnica da psicanálise. Rio de Janeiro: Jorge Zahar, I985

. "Some reflections on the ego". I95I. Disponível em: <http:// aejcpp.free.fr/lacan/I95I-05-02.htm>. Acesso em I2/06/2008.

OGILVIE, B. Lacan: la formation du concept de sujet. Paris: Presses Universtaire de France, I988.

SALES, L. S. Determinação versus subjetividade: apropriação e ultrapassagem do estruturalismo pela psicanálise lacaniana. Tese de doutorado. São Carlos: UFSCar, 2008. 
• "Posição do estágio do espelho na teoria lacaniana do imaginário". In: Revista do Departamento de Psicologia, UFF, v. I7 - $\mathrm{n}^{\mathrm{O}} \mathrm{I}, \mathrm{p}$. II3-I27, Jan./Jun. 2005. Disponível em: 〈http://www.scielo.br/pdf/rdpsi/vi7nI/vi7nIaO9.pdf〉. Acesso em I2/06/2008.

SAFATLE, V. Lacan. São Paulo: Publifolha, 2007. A paixão do negativo. São Paulo: Unesp, 2005.

PROUST, M. A fugitiva. São Paulo: Globo, I989.

TORRES, R. "Lacan e Hegel”. In: Psicologia USP, I5(I/2), 309-320, 2004. Disponível em: <http://www.scielo.br/pdf/pusp/vI5nI-2/a27vI5I2.pdf〉. Acesso em I9/06/2008.

Luiz Fernando Botto Garcia é graduando em Filosofia pela USP.

E-mail: 1fbotto@gmail.com 